\title{
Balint's syndrome in subacute HIV encephalitis
}

\author{
A Schnider, $T$ Landis, M Regard
}

\begin{abstract}
A 45 year old patient with AIDS is described in whom Balint's syndrome developed over several days without other higher cognitive defects. Radiological findings were typical of subacute HIV encephalitis involving mainly the white matter of the occipital lobes with extension into the parietal and temporal lobe on the left side and into the temporal lobe on the right side. While the patient could usually recognise onily one single component within her visual field, ber performance in reading much improved if she was allowed to observe the examiner writing. This finding is attributed to well preserved movement perception in our patient, which may have helped her in directing her visual attention. The preservation of movement perception despite damage to the lateral temporo-occipital area may be due to the distinct pathology of subacute HIV encephalitis, which leaves the cortex and adjacent subcortical white matter virtually intact and therefore allows information transfer between primary visual areas in the occipital lobe and movement specific areas in the lateral temporo-occipital area through U-fibres.
\end{abstract}

Patients with Balint's syndrome ${ }^{1-4}$ have a triad of visuo-ocular disturbances: 1) Visual inattention which prevents the perception of several simultaneous events in the visual field at a time. This disturbance is usually called "simultanagnosia"; 2) Ocular apraxia, that is, an inability to fixate and follow an object with the eyes; ${ }^{56}$ 3) Optic ataxia, that is, a limb ataxia which becomes evident in goal-directed movements performed under visual control but not in movements performed with closed eyes. ${ }^{56}$ Even though Hécaen ${ }^{7}$ and Luria ${ }^{6}$ suggested that the whole triad of Balint's syndrome could be explained in terms of a narrowing of visual attention, it seems that the different components of Balint's syndrome are independent from each other as minor forms of Balint's syndrome have been described in which certain elements of the syndrome are less pronounced, ${ }^{7}$ and all components have been described separately. ${ }^{8}$ Simultanagnosia, can also be of varying degree. In the extreme form of simultanagnosia, the patient's visual attention may be so narrowed that he recognizes only one single object within the visual field. ${ }^{8}$ This form is always due to bilateral parieto-occipital lesions. In its subtler form, which was originally described by Wolpert, the patient may not be able to grasp the meaning of a picture despite preserved recognition of its elements. This disorder may arise from a unilateral left-sided parieto-occipital lesion. 10 il

Most patients who have been described with Balint's syndrome had a vascular lesion. We examined a patient with Balint's syndrome due to subacute HIV encephalitis which was diagnosed from the appearance of the MRI. ${ }^{12-15}$ The lesions mainly involved the occipital lobes and extended into the temporal and parietal lobes. In contrast to vascular lesions, this disease involves primarily the white matter of the cerebral hemispheres while it leaves cortical and adjacent subcortical white matter relatively undamaged. In fact, our patient had exceptionally well preserved movement perception despite involvement of the lateral occipito-temporal areas.

\section{Case report}

The patient was a 45 year old schoolteacher with AIDS stage IV who had already suffered from two opportunistic pneumonias a year ago, but who had not previously experienced any neurological sequelae. She had been infected through unprotected sexual intercourse and had never used intravenous drugs. Therapy with zidovudine was initiated only ten days before admittance. She was a heavy smoker with 80 pack-years. She was admitted because of visual disturbances.

She had already felt a progressive weakness of her right arm for three weeks, when she noticed an inability to perceive the properties of standing objects or persons some days before admittance. She had first realised this when she recognised only moving objects on television. In daily life, she could not distinguish between people and objects if they did not move. However, she still recognised familiar people, even though she was puzzled by not being able to see specific features, such as the colour of their hair or eyes or hairstyle. She thought she remembered newly introduced people mainly through such hints as their walk or voice. She was totally unable to read anything, even large newspaper headlines. When walking she often did not perceive obstacles on either side and repeatedly walked into them, especially into glass doors. The patient was able to walk without aid but preferred to go along the walls 
to orient herself. She found her way around in the hospital but was unable to find her bedroom as she could not read the room number. Thus a plastic bag was attached to the door which she would search for. She could eat by herself but could not cut the food because she could not find it with the knife. She could pour coffee into a cup without spilling it but had to adjust the positions of the cup and the pot carefully with tactile control before pouring.

On neurological examination, there was a right homonymous hemianopia both in the upper and lower quadrant with preserved perception of movements of the whole hand of the examiner, but not of fine movements such as the fingers. Her gaze seemed void in that her eyes moved around in search of eye contact with the examiner or when trying to fixate an object. Once she had fixed an object, her eye movements were full and she could smoothly follow it with her eyes. However, when trying to "catch" an object in her visual field with her eyes, the saccades were severely dysmetric to both sides (ocular apraxia). No other disturbances of cranial nerves were observed. There was a slight weakness of the right arm, both for proximal and distal muscles. Sensibility of the right arm and especially the right hand was diminished for all qualities, and she did not recognise objects put into her right hand. There was no upper limb ataxia on either side in the finger-to-nose trial with closed eyes. However, with visual control, she displayed severe ataxia of both arms when trying to point to an object with her index finger (optic ataxia). With both arms, this was more pronounced in the right hemispace. Muscular strength and sensibility of the legs were intact. Tendon reflexes were normal and symmetrical, and the plantar response was flexor on both sides.

On mental status examination this left handed woman was oriented for space and time. Language functions such as spontaneous

Figure 1 Examples of the
patient's visual gnosis
performance. The
drawings and the patient's
commentaries to them are
shown in the same order as
during the examination.
The thin lines overlying
some of the drawings and
scripts are trials of the
patient to follow their
outlines with a pencil.
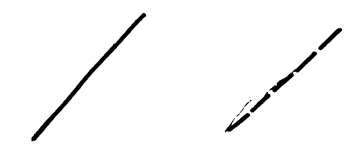

"A straight line"

"I don't see anything coherent. Something with lines"

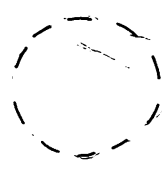

"Lines. It doesn't make any sense.
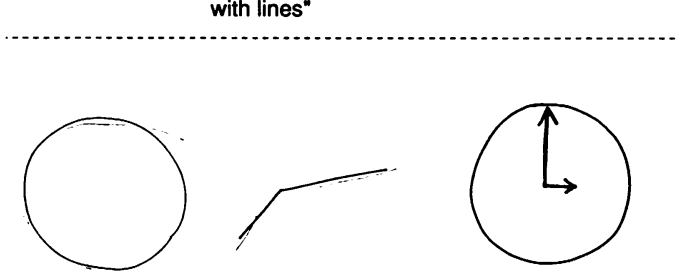

"A circle" "Two lines"

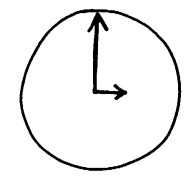

"A rather short arrow. It lacks the crossbow."
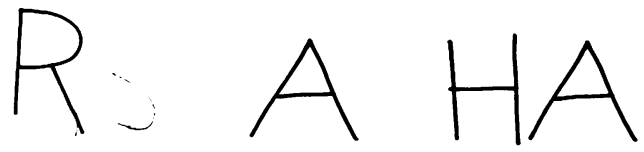

"Maybe a letter. Might be an $\alpha R_{\infty}$. I don't know where it is precisely."
"An "As" "No idea what it is!" speech, auditory comprehension, repetition, word list generation, comprehension of words spelled out to her, and naming of environmental sounds were intact. Oral calculations were correct. There was no ideomotor apraxia of the face or the arms and no finger agnosia. Verbal immediate and short term memory were intact. In a line cancellation test, she did not show hemispatial neglect, that is, she succeeded in marking all lines despite great difficulty in adjusting the position of the pencil to the lines.

Her problems were primarily visual: she wrote with correct sequences of letters with both her right and left hand but had great difficulties in aligning the letters. If she briefly interrupted the writing she could not find the end of what she had written previously and therefore could not keep to one line. There was no prosopagnosia: the patient knew most of a series of famous people on photographs and recognised the examiner after several hours even though he was wearing different clothes from those during the examination and was neither moving nor speaking. Facial emotions on photographs were recognised. She could distinguish, match, and name colours, even though sometimes she misjudged their brightness.

Examples of the patient's visual gnosis performance are given in fig 1 . She recognised drawings of single thin straight lines or a circle. However, if the drawing consisted of several lines that were crossed or if the lines were dashed (needing mental completion), she was totally incapable of identifying any form or of following it with a pencil.

The exceptions were single letters and numbers which were usually recognised if presented alone. But if two letters were shown at once, neither of them was recognised. The performance dramatically improved if the patient was allowed to observe the examiner writing. She could then read words of up to seven block letters and numbers up to three digits long. This enhancement of perception through observation was not possible for words written in script or for drawings of abstract figures, such as a triangle or a cross, or for meaningful drawings, such as a head, face, flower or tree.

A $C T$ scan revealed a hypodensity in the parieto-occipital region on the left side without contrast enhancement. In the right hemisphere, there were small non-enhancing lesions in the frontal and occipital lobe. An $M R I$ showed extensive lesions, which involved mainly the white matter, in the occipital lobes with extension into the temporal and parietal lobe on the left side and into the temporal lobe on the right side (fig 2). Furthermore, a small subcortical lesion was seen in the area of the Rolandic fissure on the left side.

The lumbar tap yielded a slight pleocytosis with 12 cells per $\mathrm{mm}^{3}$, mainly lymphocytes, while the protein content was normal. Serologic and microbial studies were negative for cytomegalovirus, toxoplasmosis, cryptococcosis, and mycobacteria.

The patient continued to receive zidovudine. On a follow up examination two months later, her visual perception had significantly 

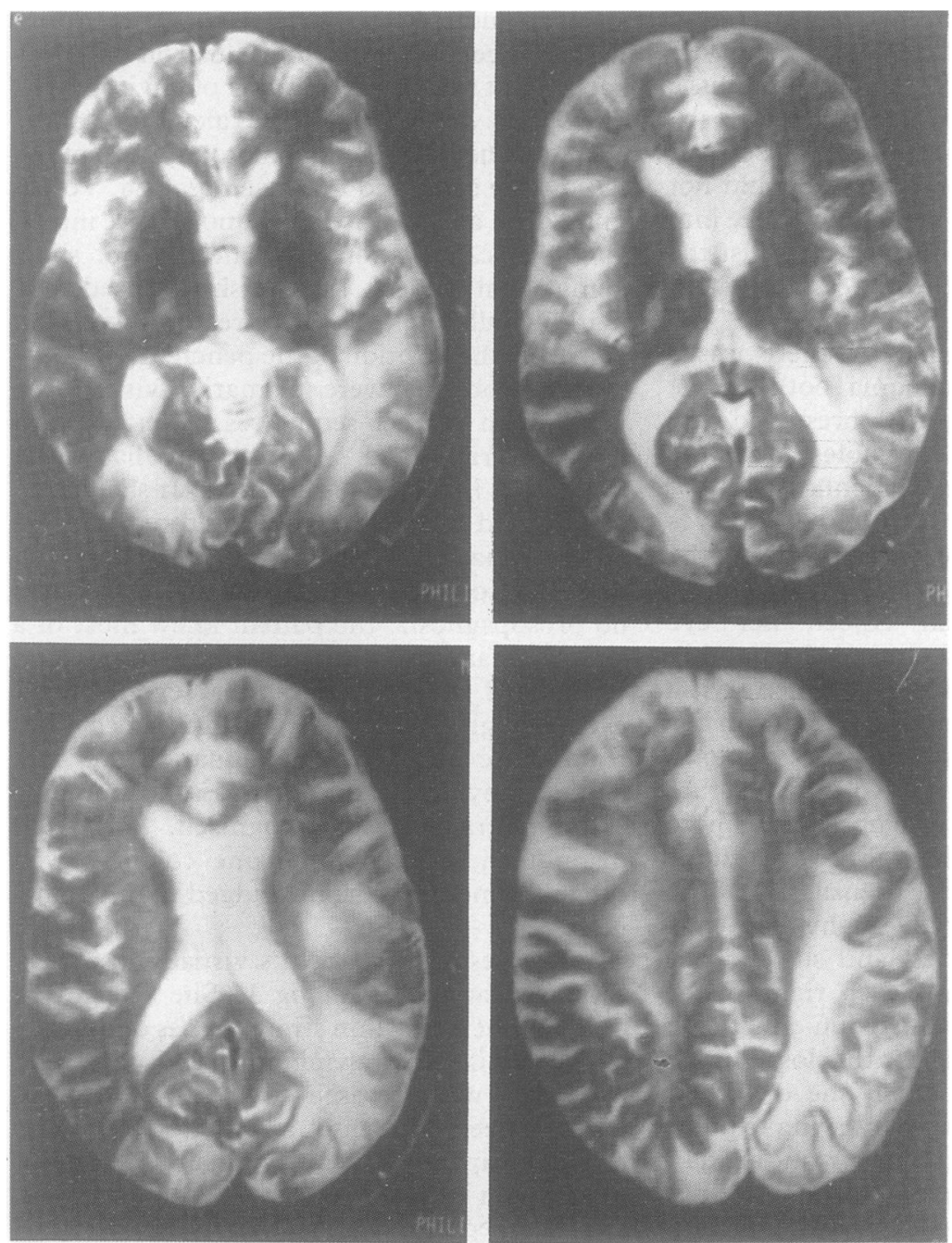

Figure $2 M R I$ of the patient $\left(T_{2}\right.$-weighted) with confluent lesions involving the occipital lobes on both sides that extend into the temporal and parietal lobe on the left side and into the temporal lobe on the right side. The left side of the images corresponds to the right side of the brain. lesions that were mainly limited to the deep white matter and spared the cortex and adjacent subcortical matter. Even though a biopsy was not performed, the MRI appearance $^{15}$ and the clinical course with responsiveness to zidovudine make a diagnosis of subacute encephalitis due to HIV most likely. ${ }^{12-14}$

While some patients with Balint's syndrome experience difficulties in perceiving movements, ${ }^{416}$ our patient was able to perceive movements and this enabled her to distinguish between objects and people. In addition to showing that disturbances of movement perception are coincident with rather than essential to Balint's syndrome, this pecularity in our patient deserves discussion. Isolated defective movement perception has been reported in a patient with bilateral vascular lesions affecting the lateral occipito-temporal cortex and underlying white matter. ${ }^{17}$ Because of the extension of our patient's lesions into the temporo-occipital junction on both sides, an impairment of movement perception might have been expected. But unlike vascular lesions, our patient's disease mainly spares the cortex and adjacent subcortical matter with the U-fibres. ${ }^{14}$ It has been shown that the information transfer from the primary visual areas in the striate cortex to the higher visual areas in the occipito-temporal junction and the temporal lobe takes place through U-fibres rather than through deep white matter pathways. ${ }^{18}$ It is therefore not surprising that certain visual properties were preserved in our patient, for example, movement perception, which is known to follow a functionally and anatomically distinct pathway. ${ }^{19}$

Form discrimination by our patient improved with the aid of motion not only in daily life but also in the test situation when asked to read. While she was otherwise only able to recognise single letters or numbers, she could read whole words and 3-digit numbers if she was allowed to observe the examiner writing. It is possible that additional kinesthetic information obtained from ocular movements by observing the examiner's hand might contribute to her perception. This kind of compensation for impaired visual recognition was described by Goldstein and $\mathrm{Gelb}^{20}$ and by Landis $e t a l^{1}$ in patients who "traced" the visually seen contours by hand or head movements and thus became able to "read" a text. In our patient, however, this explanation (that is, recognition through kinesthetic mediation), cannot account for the relative modality specificity of the ensuing improvement. This was limited to the perception of words and numbers, while the perception of abstract drawings such as a cross or a triangle, or of meaningful drawings such as a head, face, or tree, was unaffected. It is known that visual attention in normal subjects can be attracted by motion. ${ }^{22}$ The observation of the examiner writing may have attracted our patient's visual attention, thus resolving an otherwise incomprehensible array of visual components that could only be read in isolation if there was no movement. The fact that this compensation 
was possible only for block writing but not for script lends further support to this explanation. Such an interpretation implies that the visual disturbance in Balint's syndrome is due to a disorder of the spatial distribution of visual attention, as suggested by Hécaen ${ }^{7}$ and Luria. ${ }^{6}$

1 Balint R. Seelenlähmung des "Schauens", optische Ataxie, räumliche Störung der Aufmerksamkeit. Monatschr Psych Neuro 1909;25:51-71.

2 Pötzl O. Die optisch-agnostischen Störungen (Die verschiedenen Formen der Seelenblindheit). Leipzig, Deuticke 1928.

3 De Renzi E. Disorders of space exploration and cognition. New York: John Wiley, 1982

4 Damasio AR. Disorders of complex visual processing: agnosias, achromatopsia, Balint's syndrome, and related difficulties of orientation and construction. In: Mesulam MM, ed. Principles of behavioral neurology. Philadelphia: MM, ed. Principles of behav

5 Holmes G. Disturbances of visual orientation. Br JOphthalmol 1918;2:449-68, 506-16.

6 Luria AR, Pravdina-Vinarskaya EN, Yarbuss Al. Disorders of ocular movement in a case of simultanagnosia. Brain 1963;86:219-28.

7 Hécaen H, Ajuriaguerra J. Balint's syndrome (psychic paralysis of visual fixation) and its minor forms. Brain 1954;77:373-400.

8 De Renzi E. Disorders of spatial orientation. In: Vinken PJ Bruyn GW, Klawans HL, Frederiks JAM, eds. Handbook of clinical neurology, vol 45: Clinical neuropsychology. Amsterdam: Elsevier Science, 1982:405-22.

9 Wolpert I. Die Simultanagnosie-Störung der Gesamtauffassung. $Z$ ges Neurol Psychiat 1924;93:397-415.
10 Kinsbourne M, Warrington EK. A disorder of simultaneous form perception. Brain 1962;85:461-86

11 Kinsbourne $M$, Warrington EK. The localizing significance of limited simultaneous visual form perception. Brain 1963;86:697-702.

12 Kleihues P, Lang W, Burger PC, et al. Progressive diffuse leukoencephalopathy in patients with acquired immune deficiency syndrome (AIDS). Acta Neuropathol (Berlin) 1985;68:333-9.

13 Petito CK, Cho ES, Lehmann W, Navia BA, Price RW. Neuropathology of acquired immunodeficiency syndrome (AIDS): an autopsy review. J Neuropath Exp Neurol (AIDS): an aut

14 Gray F, Gherardi R, Scaravilli F. The neuropathology of the acquired immune deficiency syndrome. A review. Brain acquired immune

15 Jarvik JG, Hesselink JR, Kennedy C, et al. Acquired immunodeficiency syndrome. Magnetic resonance patterns of brain involvement with pathologic correlation. Arch Neurol 1988;45:731-6.

6 Girotti F, Milanese C, Casazza M, Allegranza A, Corridori F, Avanzini G. Oculomotor disturbances in Balint's syndrome: anatomoclinical findings and electrooculographic analysis in a case. Cortex 1982;18:603-14.

$17 \mathrm{Zihl} \mathrm{J}$, Von Cramon D, Mai N. Selective disturbance of movement vision after bilateral brain damage. Brain 1983;106:313-40.

18 Tusa RJ, Ungerleider LG. The inferior longitudinal fasciculus: a reexamination in humans and monkeys. $A n n$ ciculus: a reexamination

19 Livingstone $M$, Hubel D. Psychophysical evidence for separate channels for the perception of form, color movement, and depth. $J$ Neurosci 1987;7:3416-68.

20 Goldstein K, Gelb A. Psychologische Analysen hirnpathologischer Fälle auf Grund von Untersuchungen Hirnverletzter. $Z$ ges Neurol Psych 1918;41:1-142.

21 Landis T, Graves R, Benson DF, Hebben N. Visua recognition through kinaesthetic mediation. Psychol Med 1982;12:515-31.

22 McLeod P, Driver J, Crisp J. Visual search for a conjunction of movement and form is parallel (Letter). Nature 1988; 332:154-5. 